\title{
An Application of Using Virtual Reality Modeling Language Method to Analyze the Geophysical Data
}

\author{
Yu-Hsi Chou ${ }^{1, *}$ and Chao-Shing Lee ${ }^{1}$ \\ (Manuscript received 1 March 2001, in final form 15 March 2001)
}

\begin{abstract}
Using the Virtual Reality Modeling Language (VRML) technique, we have developed a software in which one can intelligently "walk", "slide", "examine", "point", "view" and "look" the geophysical data in a real-time mode. This technique improves data presentation and interpretation. It works better than the traditional 2-D and 3-D mapping tools. We further apply the "image texture" method in the system by which the bathymetry grid can be combined together with other geophysical data (e.g., the magnetic, gravity, earthquake and seismic reflection data); one can thus smartly analyze the integrated images. This method is in an interactivemode. As compared with other commercial batch-mode VRML, the implications are unlimited.
\end{abstract}

(Key words: Virtual Reality Modeling Language, Interactive Mode, Geophysical Data)

\section{INTRODUCTION}

Scientific computation and visualization is a technique to integrate image processing, computer mapping and programming for a better presentation of complicated data. The raditional 2-D mapping methods use such processes as iso-surface, surface plot, contour plot, cutting plane and value-to-color mapping to assist the presentation. The 3-D methods involve shading, ray tracing, perspective projection and hidden-surface removal techniques, etc. to enhance the interpretation. VRML is a new method using computer generated 3-D maps, images, video and audio to re-present an artificial reality in a virtual environment. In this technique, the tools of tele-presence and tele-existence are important for interactively transferring the data into a virtual reality world, so the user can more easily identify events and processes. This is a first step in transferring the geophysical data (e.g., the bathymetry, magnetic, gravity,

\footnotetext{
1'Institute of Applied Geophysics, National Taiwan Ocean University, Keelung, Taiwan, ROC

${ }^{*}$ Corresponding author address: Prof. Chao-Shing Lee, Institute of Applied Geophysics, National Taiwan Ocean University, Keelung 20224, Taiwan, ROC; E-mail: leecs@ mail.ntou.edu.tw
} 
earthquake and seismic reflection data) around Taiwan into the VMRL environment. We will describe the method and its implications. It is our intension to apply this method as an optional tool for analyzing the data in the southern Okinawa Trough and offshore Taiwan. The developed VRML software is now available in the web site of the Institute of Applied Geophysics, National Taiwan Ocean University (http://www.iag.ntou.edu.tw).

\section{METHOD}

The geophysical data used in this study were collected by multiple resources: the multichannel echo sounding bathymetry data from the 1996 Taiwan-French co-operated "Active Collision in Taiwan" (ACT) cruise, the magnetic and gravity data from Hsu et al. (1998), the earthquake data provided by the Central Weather Bureau, and the seismic reflection data from the ACT and R/V Chiu-Lien cruises. We integrate the above data and apply them into a VRML environment. After many tests, it is now utilized to assist the tectonic structure analyses, comparisons and interpretations of the offshore areas around Taiwan.

Three public-domain VRML tools are available in the web site (Netscape Viewer, I E Browser and Cosmo Player). We have applied these tools into our study (Hartman and Wernecke 1996; Ames et al. 1997; Fairbairn and Parsley 1997; Chang 1998). In general, VRML is a computer language that is utilized to present the reality of the data. The products are real-time 3-D images, which may change with the time and control commands. There are 10 control commands: walk, slide, examine, point, view, look, zoom, rotate, pan, and lack. One can use different commands for his or her special requirements. In this artificial environment, we use the "right-hand rule" to construct the images; the $\mathrm{x}$-axis is the right side of the screen, the yaxis is the upward and the $\mathrm{z}$-axis is the outward. There are no real dimensions in VRML.

One of the major tasks for this study is to transfer the geophysical raw data into a VRML recognized file. Table 1 shows the flow chart of this data transformation. First, we use the General Mapping Tools (GMT) software or PC-based mapping package (e.g., SUFFER and ER Mapper) to convert the bathymetry, magnetic, and gravity raw data into the grid file, and then transfer to the ASCII file. We developed our own FORTRAN program to rewrite the format into a VRML format. At this step, the 2-D geophysical map will be used to integrate with the 3-D topographic model. A preliminary VRML is ready for testing. After many trial and error tests, the user will apply it for interpretation of the data. The software developed for this study is shown as the attachment in a master thesis by Chou (2000).

The differences between VRML images and traditional motion pictures are that VRML present a real-time and interactive model, and the paths are not pre-set path ways. To display a high quality image in a real-time mode is a fundamental requirement for the VRML technique.

In order to achieve high resolution and high speed of display, we will need to introduce the methods of "texture mapping" and "level of detail" to VRML. "Texture mapping" is a method, which will use a pre-mapping picture to overlap the topographic elevation, instead of calculating the 3-D model at every step. This method has been successfully applied into VRML and increased the resolution and speed. "Level of detail" is a technique to provide different maps with different resolution. Therefore, the speed of VRML can be maintained. Both methods are important tools for yielding a better performance in the VRML exercise. Figure 1 is 
Table 1. Flow chart of data transformation.

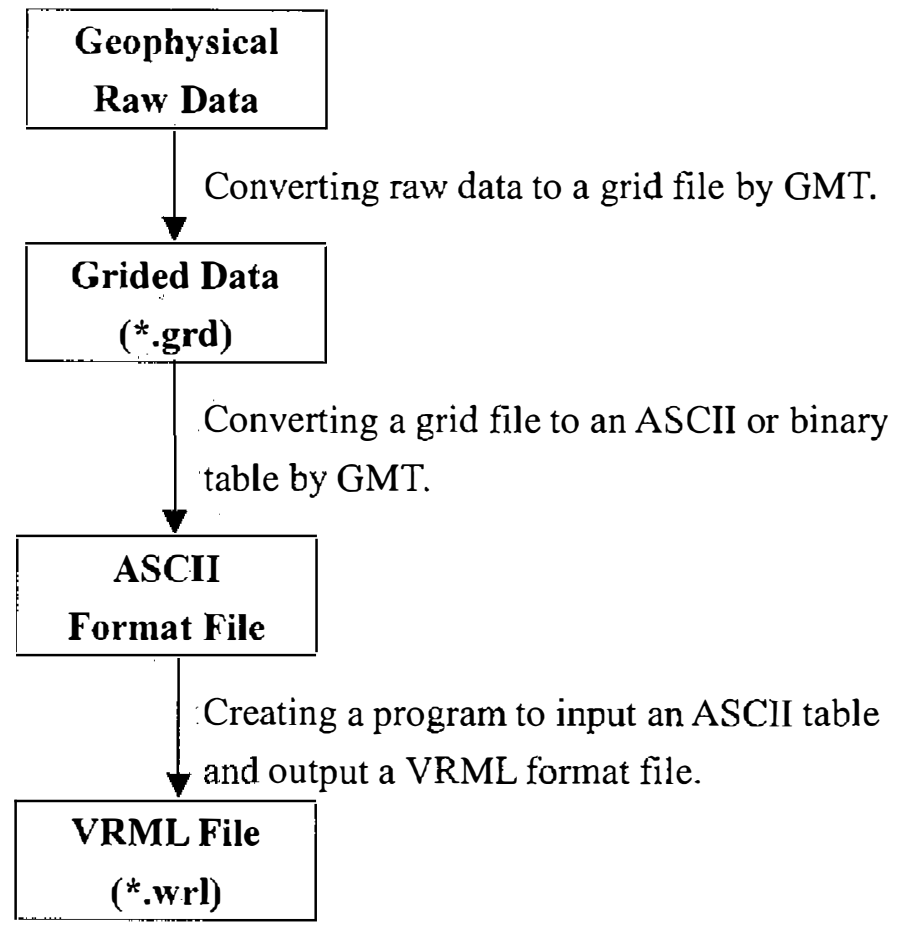

one the examples using the "texture mapping" tool to present the bathymetry (in topographic model) and the magnetic data (in colors) in one of the VRML experiments.

\section{IMPLICATIONS}

In order to improve the resolution, we not only use large-scale VRML files for regional interpretation, as shown in Fig. 1, but also apply small-scale files in the description of detailed tectonic structures (i.e., the active fault, fossil-river channel, submarine volcano and canyon). The usefulness of any scale VRML depends on the speed of a graphic re-presentation, so the user can maintain an interactive mode. Therefore, a careful selection of the area and size becomes essential for a successful VRML experiment. Several sub-files are shown in our institute's web site (http://www.iag.ntou.edu.tw). Each file has been tested for its special purposes; these are:

Grouped Volcano -There are about 20 submarine volcanoes in the middle of the southern Okinawa Trough. Applying the V.RML, the user can use any angle of view to obtain their relationship with the central grabbens of a back-arc opening. Because the volcanoes are located on the top of grabben, this implies that the volcano probably erupted after the forming of grabbens. Tseng's extensional collapse model (1990 and 1996) is best tested by this VRML experiment. 


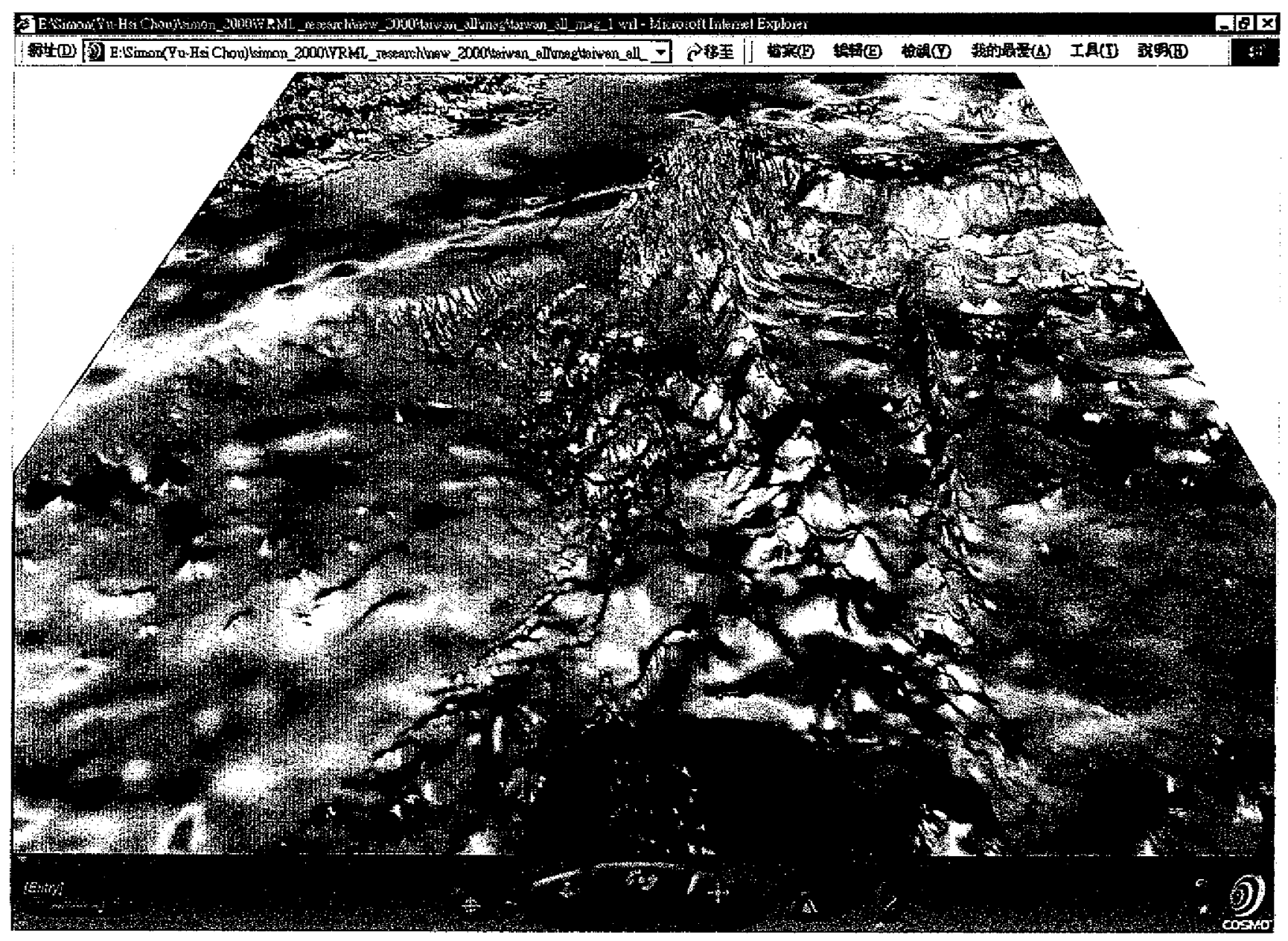

Fig. 1. A 3-D bathymetry (in topography) and the magnetic anomalies (in colors) are shown together in a VRML image using the "texture mapping" technique. The browser of the Cosmo Player is in the bottom. 
Active Fault - Chu (1997) described the Lishan Fault as extended along the eastern edge of the Hsuehshan Range and terminated in the offshore area. Using a VRML file of this area, the user can repeatedly monitor the fault extension and its tectonic association with the opening of the Okinawa Though.

Submarine Canyon - According to Yang (1997), the Mien-Hua Canyon is a V-shaped canyon, with a displacement of about 300-500 m. When we applied a "texture mapping" technique into the VRML presentation for bathymetry and magnetic data, we found these magnetic anomalies were associated with the locations of active volcanoes as described by Tsai (1999). This implies an active tectonic origin, instead of something in the nature of erosion surface and/or river submerge.

Fossil-River Channel - There are at least 3 sections of fossil-river channels shown in the multichannel echo sounding data in the southem Okinawa Trough (Sibuet et al. 1998). As a display of the VRML images, we can better observe that the river channels have been interrupted at least 3 times during the opening of the central grabben; and it is consistently shifting to the north. This implies that the channel termination may due to a large-scale volcanic eruption. ODP Drilling Site - A VRML file was created to assist the monitoring of the seafloor condition near a proposed ODP KS-1 drilling site in the southem Okinawa Trough. Using the "texture mapping" technique, we can display various of geophysical data in the same image and improve the site evaluation.

\section{CONCLUSIONS}

1. To display the images in a real-time mode will require a huge amount of memory in the computer. We have tested it in our Pentium-III PC; a size of $1000 \times 800$ grid is about the maximum size for its capacity. Therefore, a careful selection of the sub-file is important. For this reason, we maintain as many sub-files as possible in our system.

2. The VRML can be used in connection with the Internet. We are in the processes of developing it for the purpose of remote teaching.

3. At this step, we have utilized the video presentation of the VRML. The audio presentation is another field that can be developed in the future. The implications are unlimited.

Acknowledgements This work was supported by the National Science Council of the Republic of China under grant NSC 89-2611-M-019-008-ODP. The authors would like to thank Mr. Zen-Shou Chang for providing an early version of VRML program, and Dr. Char-Shine Liu for the seismic reflection data.

\section{REFERENCES}

Ames, A. L., D. R. Nadeau, and J. L. Moreland, 1997: VRML 2.0 Sourcebook. John Wiley \& Sons, Inc. 140pp.

Chang, Z. S., 1998: Some particular characteristics of the topography in Southern Okinawa Trough: an application of VRML. MS thesis of National Taiwan Ocean University, 
32pp.

Chou, Y. H., 2000: An application of using Virtual Reality Modeling Language method to analyze geophysical data in Southernmost Part of Okinawa Trough. MS thesis of National Taiwan Ocean University, 84pp.

Chu, H. T., Y. Wang, and B. S. Yu, 1997: Lead-Zinc quartz veins of the Chinmienshan, Toucheng, northeastern Taiwan. J. Geol. Soc. China, 40-1, 225-242.

Fairbairn, D., and S. Parsley, 1997: The use of VRML for cartographic presentation. Computer \& Geosciences, 23, 475-481.

Hartman, J., and J. Wernecke, 1996: The VRML 2.0 Handbook. Addison-Wesley Publishing Company. 217pp.

Hsu, S. K., C. S. Liu, C. T. Shyu, S. Y. Liu, J.C. Sibuet, S. Lallemand, C.S. Wang, and D. Reed,1998: New gravity and magnetic anomaly maps in the Taiwan-Luzon region and their preliminary interpretation. TAO, 9, 509-532.

Sibuet, J. C., B. Deffontaines, S. K. Hsu, N. Thareau, J. P. Le Formal, C. S. Liu, and ACT party, 1998: Okinawa Trough backarc basin: early tectonic and magmatic evolution. $J$. Geophys. Res., 103-B12, 30245-30267.

Tsai, C. H., 1999: Submarine volcanoes and hydrothermal circulation in the Southernmost Part of Okinawa Trough: An Initial Study. MS thesis of National Taiwan Ocean University, 82pp.

Yang, M. L., 1997: Morphological structure of the northeastern offshore area of Taiwan and its tectonic implications. MS thesis of National Taiwan Ocean University, 6lpp. 